\title{
SEMANTIC PRIMES OF PERCEPTION FROM THE PERSPECTIVE OF WORD FORMATION
}

\author{
Anna ZASLONKINA \\ Yuriy Fedkovych National University, Chernivtsi, Ukraine
}

\begin{abstract}
The object of the present study is the domain of Greimassian semiotic theory. Several previous findings on supraindividual phenomena have been summarized and theoretical underpinnings of the so-called thymic category have been extended. Investigation of such an object discloses the relation between the experiential (which approximates the sensational) and the cognitive nature of perception. Whereas conceptual universals that bear the information on feelings, senses and emotions such as those inherent in the corporal framework which correspond to the basic level of categorization have already been demonstrated, their iconic efficiency in terms of Peircian semiotics is still unclear. Therefore, the aim of the current analysis is to clarify structural-semantic links between derived and root words constituting the thymic lexical corpus of modern English. This paper emphasizes the importance of understanding how the motivational means conditioned by the classification of associative-figurative and evaluative features of the conceptual triad SENSE: FEELING : EMOTION are exteriorised within the thymic category. These characteristics can be developed and enhanced through the iconic reflection of the correlation between the native speakers' evaluation of the sign acting as a motivator and the expressive as well as gnoseological functions of perception.
\end{abstract}

Keywords: composite; concept; derivative; icon; word formation

\section{Introduction}

Conceptualization of various details of objective reality via linguistic consciousness is determined by the polymodality of perception, which involves the unity of emotional, volitional, intellectual, and physical states within the holistic cognitive-semantic context of corporeality (Pryhodko 237-38; Putiy 9598). The human organism as the basis for interpreting divergent phenomena of perception has become a vital enterprise in semiotic research. In particular, both 
corporeal semantics (Damasio 1999; Fauconnier 1998; Gärdenfors 2000) and the integrative theory of cognition (Poznanski 2002) foreground the immediate role of body and emotions in cognitive processes. Likewise, the relationship between perception, language, thinking, and action makes a conspicuous headway in the semiotics of the sensible, i.e. studies of Greimas and Fontanille (Greimas, Fontanille 2007), further developed by Schleifer (Schleifer 2017). Greimas applied his theory to the so-called thymic category (from the Greek word thymus meaning "related to passions and emotions within the entire physical structure of the human organism" (Greimas, Fontanille 13)). Therefore, the human cognitive activity results in the formation of a clear-cut category which generalizes and classifies the knowledge structures about perceptual, cognitive, and emotional facets of perception evolving around the accumulation of their similarities.

Differentiation between symbols, icons, and indices within a category has marked a new approach to the understanding of the term concept: "the words are the signs of concepts and it is round the latter that the categories form" (Kubryakova 318). One of the outcomes of classifying our contexts is revealing meaningful entities that signify something. In this respect the sign represents a category as "an entity that is being singled out according to a certain index, notably its ability to be the information carrier (to have content)" (Kravchenko 75-76).

This paper aims to contribute to the development of Peircian and Greimassian semiotics by problematizing the structure and content of the thymic category with regard to cognitive linguistics. Such task requires the selection of concepts sufficient for the thymic category to form, as well as the description of the singled out lexical concepts in terms of form-meaning iconicity.

With regard to semiotician Peirce's belief that "any operation of consciousness however complicated it might be, obtains its pure sensationemotion tout ensemble" (131), it is hypothesized that the concepts SENSE, FEELING, EMOTION are the entitities that form the basic level of the thymic category. The notional thymic potential of the conceptual triad SENSE : FEELING : EMOTION is enhanced by means of lexemes which are derivationally connected with the ternion's basic nominals. The thymic lexis corpus inventory has demonstrated the existence of word-forming structures that actualize themselves due to word-formation processes on the basis of the arrangement of invariant-morphemes present in the English language or on the basis of compounding.

The distinctive cognitive axes or word-forming components ensure the pragmatically appropriate interpretation of the thymic lexemes, thus making the word-forming act tantamount to the categorization act. In other words, "provided inclusive-graded nature of abstraction, the lexical derivation can be regarded as a verbal manifestation of the generalised invariant semantic salience" 
(Ufimceva 67). Structural semantic links between derived and root words (basic and marginal thymic lexical units) exteriorise the motivational means conditioned by grouping associative figurative and evaluative features of the conceptual triad SENSE : FEELING : EMOTION within the thymic category.

\section{Idealization of the Thymic Category}

It can be argued that perceiving as a unit of the lexical-semantic system of the English language actualizes as a part of the lexical paradigm, thus making it possible to interpret this lexeme as the name of the synonymical chain formed by the lexical units correlating with perceiving's semantics.

Despite the extensive capacity of the structural-semantic system of conceptual groups denoting the perceptual, cognitive and emotional facets of perception, semantic elements (nouns) can be identified among the thymic category members, mainly the nouns that constitute the ontological minimum of the alleged category expressed through the basic characteristic. The latter indicates the elementary character and indivisibility of the lexical unit, its ability to be of importance in the other lexemes' definitions.

The analytical approach to the classification of semes pertaining to the meaning structures of the lexemes sense, feeling, emotion is an extension of the research work by Putiy (Putiy 2006) by its inductive directivity: the analysis of the thymic category in general and of the notion of perceiving in particular is stipulated by the analysis of the basic concepts constituting the presumed triad SENSE : FEELING : EMOTION around which the thymic category is unfolding.

Componential analysis will help reconstruct the semantic connections among the meanings of the lexemes SENSE and EMOTION. Componential analysis seems logical because the lexical-semantic language structure comprises interconnected and interdependent elements. The correlation of words according to their meaning is an eminent manifestation of language consistency. In other words,

paradigmatic word relations occur provided that there are common semes in the word meaning and these semes duplicate in the sememes of other words. Classeme is a nuclear component of the word's definition, the essence constituting the class of paradigmatically related words. In a subclasseme the words are linked by an integrative seme that groups lexical units according to their primary meanings thus attributing the superordinate concept denoted by the word to a certain class (Selivanova 182).

Definitions selected from the American Heritage ${ }^{\circledR}$ Dictionary of the English Language, Fourth Edition, Century Dictionary and Cyclopedia, GNU 
Webster's 1913, Wiktionary, and WordNet 3.0 constituted the data for the present study.

As a result of systematization and alignment of the semes of the lexemes sense, feeling and emotion, the componential makeup of the latter lexeme revealed its orderly structure. The classeme consciousness is typical of the three lexemes under study supporting the opinion that "it is consciousness that comprises the idea about the person's sensations, emotions, and feelings" (Concise Dictionary of Cognitive Terms 176). Even so, the speech community's experience of classifying objectifies in language forms the types of mental representations of what has been perceived and realized, integrating these forms rather than opposing them. The classemes feeling, perception, understanding contain the information on the semiotic interdependence of perception and consciousness. Damasio made congruous assertions analogizing "knowing an emotion" and "feeling a feeling" (160), and so did Volf propounding that "cognitive causes of emotions are requisite to the same degree as physiological ones" (217-18).

So, the seme typology of the lexemes sense, feeling, emotion can be based on the three criteria, scilicet corporeality (integrative semes include body, physical, sensibility), cognition (integrative semes are mind, consciousness, conscious), and emotivity (integrative semes subsume pleasure, pleasurable, pleasing, sensibility). Other integrative semes discovered in the subclassemes of sense and feeling encompass touch, sensation, mental, experience; subclassemes of sense and emotion contain the integrative seme feeling; in the subclassemes of feeling and emotion the integrative semes soul and painful were found.

The presence of the integrative semes with partial overlappings in the subclassemes of the lexemes sense, feeling, emotion is marked by the variety of language means correlating with the thymic category as well as by the coherence of thymic characteristics distribution in the lexemes' definitions. The subclassemes of sense and feeling correlate due to the integrative semes touch, sensation prioritizing the meanings of corporeality. Similarly, the subclassemes of sense and feeling correlate traceable to the integrative semes mental, experience prioritizing the meanings of cognition. The subclassemes of feeling and emotion correlate as well because of the integrative semes soul, painful prioritizing the meanings of emotivity. The integrative seme feeling indicates the isomorphic features of the lexemes sense, emotion, consequently "feeling" can be regarded as archiseme (the consolidative component of the meanings of the triplet sense, feeling, emotion).

Moreover, in the typology of the key components of the already considered definitions hierarchical relations were observed. When the lexeme sense is isomorphic to the lexeme feeling, the criteria of corporeality and cognition are the combinatory factors. In the same way, when the lexeme feeling is isomorphic to the lexeme emotion, the criteria of emotivity and cognition 
function as combinatory factors. Hence, the hierarchical relations as well as semasiological overlappings in the definitions of the words sense, feeling, emotion give grounds for resorting to the conceptual triad SENSE : FEELING : EMOTION occurring at the basic level of categorization and, when verbalized, mediating the description of the knowledge structures about perception.

Overall, reciprocal relations between perceptual, cognitive, and emotional "thymic states" (the term introduced by Greimas and Fontanille (267)) clarify the intrinsic similarity of the lexical units sense, feeling, emotion emphasizing their threefold marginality. When investigating the language expression of the thymic category members, the thymic category itself is regarded as a linguistic construct of the basic categorial level, whereas the thymic nouns sense, feeling, emotion are labeled basic and the thymic lexemes belonging to different parts of speech as well as collocations and idioms are labeled marginal or peripheral.

\section{Iconic Aspects of Linguistic Processes}

The innovative model of the linguistic sign, the one that enables the synthesis of anthropocentrism and system-centrism, currently lays the foundation for approaching the principle of the sign's asymmetric duality. The asserted model came to Ohui's notice, who highlighted that

the ideal side of verbal signs, especially words, is a result of the threefold deflection of: a) objective reality in the individual's consciousness (as a notion of extralinguistic level); b) a notion in the context of the language system; c) linguistic meaning through individual / interindividual linguistic experience (the one that constitutes the pragmatic aspect of the sign, the latter being determined by the communicative activity of its producer) (25-26).

In this research signification as a means of creating and using signs is considered the impetus for the signs' instrumental function that results in the production of a notion. Because signification is a process of cognition, the sign is viewed as the focus of cognition. The sign is functioning, denoting, signifying, and bearing the meaning. Accordingly, the instrumental function of the sign is reduced to the exchange of ideas, conveying the meaning via signs. In that case the meaning can take the semiotic form only, whereas anchoring certain meanings to the shape of signs fosters thinking, thus turning the language into the means of cognition.

In the present paper "information" is defined as "a totality of knowledge reaching an individual through different channels in the form of feelings, signals or stimuli over world perception" (Concise Dictionary of Cognitive Terms 35- 
37), while knowledge itself is regarded as "the semantic content of mental representations" (Concise Dictionary of Cognitive Terms 28). Similarly, the information which can be exhibited in the form of signs as a product of the processing of knowledge of the perceptual, cognitive, and emotional facets of perception is termed conceptual thymic information. Then, the purported type of information appears an indispensable condition of the semiosis, as the verbalization of perceptual, cognitive, and emotional experience takes place through its transposition by means of an ensemble of implicit associations.

At the empirical level the presence of the linguistic sign is related to the conceptual thymic information. As Jakobson stated: "signans is perceived, whereas signatum is seized by the mind, and, in fact, interpreted" (Jakobson, 268). Taking into account the fact that "the five senses are fulfilling their own semiotic function" (Kubryakova 496), the signs related to them can be classified on the basis of the subject matter that functions as the medium of the sign, i.e. represents precise meanings (actually, the lexical units emotion, sense, feeling are the nominates of the respective facets of perception).

Within the semantic structure of the verbal sign "the information about the image schemata of the world's realia is verbalized and recoded in the course of their direct impact on the sense organs" (Lyons 424-25). The image schema's subjectivity generates its peculiarity, chiefly "dependence on emotions and unique perceptual capabilities of a person" (Kravchenko 95); indeed, the image schema is contingent on the conceptual thymic information as a product of knowledge structuring. Consequently, objects and phenomena reflected in the image schema become the content of the latter. In its turn, the content forms the semantic structure of the linguistic sign, thus making the sign a comprehensive recoder of figurative information. This premise is in line with Benedetti's findings (214).

Furthermore, the semantic structure of the linguistic sign contains several ranks: firstly, perception, that is a totality of interrelated thymic meanings; secondly, formation of the semantic content of the image schema by means of the sensory-perceptual reflection. Yet, in the process of schema verbalization the reflected qualities of the perceived objects do not acquire the status of semes, because the mental representation of such schema is still syncretic.

When the usage of the sign presupposes "the reaction not to the symbolized object, but to the whole range of secondary conventional meanings, the sign becomes a symbol" (Sechehaye 2003). Symbol and sign share common characteristics: both are formed in accordance with the ternary model (signifier - signified - semiotic connection) and both are conventional. However, the symbol is dissimilar to the conventional sign due to the iconic element - the affinity between the plane of expression and the plane of content. 
Occurring in the process of semiosis, linguistic signs finalize devising their inner structure which depends on the type of correlation between a signifier and a signified (both of them are marked by two modes of presence complementary to the symbolic one, namely iconic and indexing (Anderson 2011; Jakobson 1971; Pierce 2000). The interpretation of each mode is mediated by the conceptual thymic information. That is to say, the iconic character of signs is applicable for the description of phenomena at the generalization level where they are perceived, whereas the nature of indexing is confined to dynamic as well as space connection between the object and the feelings of an individual for whom this object serves as a sign.

\section{Word-Forming Paradigms of the Thymic Lexemes}

The analysis of the thymic marked word-formation in modern English correlates with conceiving the means of information processing, the information itself having been obtained in an experiential way. The derived word reflecting the relation between the verbal and the conceptual is structurally more sophisticated than the root word. Moreover, the derivative is more explicit and significant in terms of meaning. The word-forming type of meaning is determined by the categorial meaning of the base morpheme as well as by the meaning of a wordforming component and the framework of the semantic interaction between them.

Conceptual precepts of both basic and marginal thymic derivatives are determined by the verbal form of their representation: "the word-forming model is acting as coordinator of the cognitive structure of the derived word" (Poliuzhyn 151). The reconstruction of the thymic derivatives of the conceptual triad SENSE : FEELING : EMOTION was reduced to the morphemic segment according to the number of its constituents, making it possible to model three word-building paradigms, each of them containing a repertory of models differentiated pursuant to the part of speech affinity of the root word.

The word-building paradigm of the verbalized concept EMOTION includes: the verbal model (to emote, to emotionalize); the noun model (emotion(-s), emotionality, emotionalism); the adjectival / adverbial model (emotive, emotional, unemotional, emotioned, emotionless, emotionally, unemotionally).

The word-building paradigm of the verbalized concept FEELING encompasses: the verbal model (to feel); the noun model (feel, feeler, feeling($s)$ ); the adjectival / adverbial model (feeling, unfeeling, feelingly, unfeelingly).

The word-building paradigm of the verbalized concept SENSE comprises: the verbal model (to sense, to sensitize, to sensate, to sensify, to sensualize, to sensationalize); the noun model (sense $(-s)$, sensist, sensation, sensationalism, sensationalist, sensationism, sensibility(-ies), sensitivity (-ies), 
sensitiveness, insensitivity, sensitization (-isation), sensitizer, sensor, sensuality, sensualism, sensualist, sensuousness); the adjectival / adverbial model (senseless, sensational, sensible, insensible, sensitive, insensitive, sensory, sensual, sensuous, senselessly, sensationally, sensibly, insensibly, sensitively, sensually, sensuously).

Each word-building paradigm is characterized by its own order of semantic components arrangement depending on the efficiency of wordforming stems. The trichotomy of wordbuilding paradigms of the names of concepts SENSE, FEELING, EMOTION is tagged as a thymic substratum of moderm English iconic signs. If to regard iconic signs as means of representation of extralinguistic content of a verbal sign, the utmost iconic encoding is accomplished principally in word-formation.

Affixes with axiological significance function as means of specification or alteration of lexical or grammatical semantics of the inflection patterns with perceptual, cognitive, and emotional features. The above mentioned affixes are the principal levels of subjective modality exposition, the latter determining the referential spectrum of the thymic nouns, verbs, adjectives, and adverbs.

The gridiron of affixes is manifested by productive suffixes forming the thymic nouns: -er (feeler, sensitizer), -ist (sensationalist, sensist, sensualist), ness (sensitiveness, sensuousness), -ism (emotionalism, sensationalism, sensationism, sensualism); and by non-productive suffix with the analogous grammatical category function -ity (emotionality, sensitivity, insensitivity, sensuality).

The thymic adjectives are formed provided that the following types of suffixes are added to their stems: productive suffixes -ed (emotioned), -less (emotionless, senseless), non-productive suffixes -ous (sensuous), -ible (sensible)), productive prefix -un (unemotional, unfeeling), and non-productive prefix -in (insensitive). Adverbs as adjectives' extenders demonstrate the fixed formation order involving the productive suffix -ly, e. g. feelingly, sensibly, emotionally. The regular affixes, i.e. the word-forming modus operandi of the thymic verbs display the suffixes -ize (to emotionalize, to sensationalize, to sensitize, to sensualize), -ate (to sensate), -fy (to sensify).

In the present research the inner form of conceptual relations initiated by derivational processes is adjudged the morphological motivation mode. The motivation activates the epidigmatic relations in the language system which are conditioned by associative-figurative or evaluative perception of the signified phenomena, the latter are observed and recognized by the nominators.

As Arutjunova has proven, among all modi of the motivational basis of the onomasiological structure of thymic derivatives "the sensory evaluation is the most individualized assessment category" (85). This premise is validated by the fact that word-forming root sense bears intense productivity, because the sensor-type motivators cover the widest gamut of word-building formants. This 
provides tangible evidence on the implication of the verbal-pragmatic form with perceptual and somatic semantics for the nomination of cognitive-emotional nuances of the individual's life. These results correspond with the linguistic maxim stating that sensory processes are establishing the individual's closest contact with the objective world and provide the basis for the further mental processing. As Lukjanova asserts, "emotional and rational attributes of evaluation correlate with sensory evaluation" (45).

As a matter of fact, the selection of the lexemes constituting the wordbuilding paradigm of the verbalized concept SENSE testifies to the presence of the derivatives with mutative word-forming meaning. In particular, only the first component of the word-forming chain sensation - sensational-sensationallysensationalism-sensationalize bears sensory semantics. The other derived words within the chain demonstrate the sensory-cogitative conversion of their key informational component: tactual sensation. As a result of blending sensory and axiological meanings in the derivatives, the new notional content is observed, brought about as the effect of emotional perception, namely spectacularity. This may be attributable to the regular quality of the conceptual thymic information, when the verbal objectification of the information on the inward (mental) modes of a human's being is concurrent with the information on the corporeal (somatic) modes.

The integration of the emotional component into the sensory evaluation is confirmed by the occurrence of stereotyped axiological antinomies in the word-building paradigm of the verbalized concept SENSE, such as sensitiveinsensitive, sensible - insensible. Similar oppositions were observed in the wordbuilding paradigm of the verbalized concept EMOTION featuring emotional and axiological semantics. It is also the case that word-forming potential of a given root word is stipulated by the verbalization of supplementary emotional stimuli, when regular affixes are attached to the root (un-emotion-al, emotion-ed, emotion-less).

The word-building paradigm of the verbalized concept FEELING is characterized by a distinguishing iconic and onomasiological configuration, that is to say its morphemic segment contains the lowest quantity of the derivatives' diversity compared to the similar paradigms of SENSE and EMOTION. In the nominative acts of the English language the expressive motivation is projected onto the sensory and emotional spheres leaving a lexical gap in the place of feelings. The relocation of the semiotically fixed mental unit for the emotional sphere triggers the pseudomotivational processes in the word-building paradigm of the verbalized concept FEELING: the denotation (identified with a symbol's meaning) of the marginal thymic lexemes feelingly, unfeelingly is completely synonymous to the that of the marginal thymic lexemes emotionally, unemotionally. 
Even so, non-derivative polysemants feel, feeling partially compensate for the lack of the corresponding derivatives due to flexible modifications of their lexical-semantic variants. The definitions of the lexemes in question disclose the semantic scope of the verbalized concept FEELING: the latter varies from denoting physiological and perceptual states (to experience something physical $=$ to feel) to opposing cognitive state to the emotional one (to react using emotions instead of thinking $=$ to feel) or merging them (thoughts and attitudes $=$ feelings, opinion $=$ feeling .

Because the motivated verbal sign is iconically (through its external form) related to meaning, the formal semiotic structure fixes the cognitive model of the information activated by this sign. Therefore, the motivational configurations of the verbalized concepts SENSE and EMOTION are more meaningful and semantically sinewed than those of FEELING. Nonethless, the correlation of perceptual, cognitive, and emotional meanings within the wordbuilding paradigm of the verbalized concept FEELING is more compact and the motivators feel, feeling are semantically succinct enough to minimize the need in additional motivational configurations.

\section{Composite Words with Thymic Semantics}

From the perspective of compositional semantics composite words with the thymic referent gain a new research vector: "cognitive-onomasiological structures are not doublets of associative-figurative ideas, but rather generalized abstract mental schemata yielding the way of knowledge acquisition" (Serebrennikov 181).

Fixed sensory and / or cognitive-emotional notions verbalize the cycles of perception and precondition semantic integration of basic as well as marginal thymic lexemes. Following Toporova in respect of the cognitive modelling aspect, "the conceptual schemata of the iconic relations" (91) among the thymic category members, i.e. "conceptual-semantic series" (91) relevant to the thymic substratum of moderm English iconic signs, were partitioned.

The conceptual-semantic series fulfil their motivational potential in two dimensions: they are projected onto adjectival and nominal modules. The following series are the constituents of the adjectival module: noun-stem + adjective-stem (feel-good, price-sensitive); adjective-stem + adjective-stem (sensori-motor); noun-stem + participle-stem (heat-sensing); adjective-stem + participle-stem (remote-sensing); prefix + adjective-stem (non-sensory). The nominal module contains the series noun-stem + noun-stem: sensation-monger, sense-organ, sense-pause, sensitometer.

The thymic composite words are characterized by athematic and thematic stem derivation. The former is observed in the composite words like sense-pause, feel-good, etc. which are examples of juxtaposition, when 
composite words are written with a hyphen. The latter may be illustrated by the noun sensitometer, where two stems are combined by the interfix (an empty morph -0-).

The "propositional motivation type" (Lakoff 180) is inherent in the majority of the above described conceptual-semantic series, when onomasiological features of the thymically marked situation are transferred to a class of objects. Specifically, equonymic motivation is represented by the sensori-motor composite: "sensory" and "motor" are the significates of one level of generalization and denote a single class "certain areas of the brain".

The names of the thymic characteristics of a mingled motivation type are formed as a result of the hyperonym and hyponym integration, as in pricesensitive, sense-pause, remote-sensing; moreover, these names can function as hyponyms (price-sensitive, sense-pause) and hyperonyms (remote-sensing) within the framework of conceptual hierarchical relationships of the propositional structures of thymic lexemes.

Unlike the propositional motivation type, the associative-terminative motivation is characterized by the following semiotic regularity: the real belonging of the object to a certain class is renounced, instead its inclusion in the alogical category is observed. For instance, in the composite noun sensationmonger the associative complexes integrate analogically: a dealer in sensations / news $\rightarrow$ purveyor of what has caused widespread public excitement.

The process of the thymic composites' formation is not always comprehensively systematized in lexicographic sources. In modern English reserves of formal-semantic word-building tactics are discovered, for example the below-cited composite adjectives are contextually produced:

A truck ferried a dozen armed men to Knot's vicinity in half an hour, following his trail with a heat-sensing device so that there was no hesitation (BNC). Staff of the Remote Sensing Group are preparing a new remote-sensing training manual for geologists in developing countries (BNC). The term ,sensor" needs to be considered to include various degrees of irreversibility in the sensor-analyte interaction (BNC).

Thus, the formation of composite words with the thymic meaning reflects the cognitive aspect of the semantization of perception. Nominative structure of the composites in question is completed via iconic means when the former is projected onto semantic links existing between onomasiological features. Iconic relations occur as a result of the correlation of the thymic meaning of one motivator and non-thymic meaning of another one of each composite word. 


\section{Conclusions}

Discrepancies between Saussure's formalism and Pierce's philosophical pragmatism have stipulated re-emphasis of linguistic doctrines: they deviated from retrospective ideas to the avant-garde ones, interwoven with speculations on indices, which suggest that the sign's status is determined by its pragmatic nature. Linguistic signs are concurrently a means and a product of purposeful activity and their ontology is thymic. This is chiefly because conceptual thymic information requires verbalization as a content of consciousness and being embedded in language presupposes the alteration and evolvement of the semantic structure of the linguistic sign.

Accordingly, the distribution of cognitive-onomasiological capability within the framework of derivatives of the verbalized conceptual triad SENSE : FEELING : EMOTION fluctuates. The iconic character of the conceptual complex under study is one of the means of naïve worldview reconstruction in course of word-formation, notably the iconic aspect is marked by cognitive-semantic shift of the thymic-neuter indices of the conceptual thymic information (see FEELING word-building paradigm) to its thymicextremal analogues (see SENSE and EMOTION word-building paradigms). This could be a result of the fact that the shift of a given type is based on the correlation of evaluation of the sign-motivator and expressive-gnoseological functions of perception performed by the native speakers.

The reconstruction of the thymic composites domain reveals that the motivators of sensory type prevail. Besides, the cognitive-semantic shift was detected: the motivators (bearers of cognitive-emotional semantics) are represented by the derivatives of the verbalized concept SENSE, while the concept EMOTION is lacunary, a fortiori the composite words with feel and sensation constituents are semantically more mobile and expressive.

\section{Works Cited}

Anderson, J. M., Linguistic Representation (Trends in Linguistics: Studies and monographs), Berlin, Mouton de Gruyter, 2011.

Arutiunova, N., Tipy jazykovyh znachenij. Ocenka. Sobytie. Fact. [Types of Linguistic Meanings. Evaluation. Event. Fact], Moscow, Nauka, 1988.

Benedetti, G., "The semantics of the fundamental elements of language in Ernst von Glaserfeld's work" in Constructivist Foundations, 6/2 (2011).

Damasio, A., The Feeling of What Happens: Body and Emotion in the Making of Consciousness. New York, Harcourt Brace, 1999.

Fauconnier, G., Mental Spaces: Aspects of Meaning Construction in Natural Language, Cambridge, Cambridge University Press, 1998.

Gärdenfors, P., Conceptual Spaces: The Geometry of Thought, Cambridge, MIT Press, 2000. 
Greimas, A. J. and Fontanille Jacques, Semiotika strastej. Ot sostojanija veshchej $k$ sostojaniju dushy. [Semiotics of the Sensible. From the State of Matter to the State of Mind]. (I.G. Merkulova, Transl.), Moscow, 2007.

Jakobson, R. "World and Language" in Selected Writings in 6 volumes (Volume II). Ed. Stephen Rudy, Paris, Mouton, 1971.

Kubryakova, E. (ed.), "Knowledge”, "Information", “Consciousness". Kratkij slovar cognitivnyh terminov. [Concise Dictionary of Cognitive Terms], Moscow, MGU, 1997.

Kravchenko, A., Znak, znachenie, znanie. Ocherk kognitivnoj filosofii jazyka. [Sign, Meaning, Knowledge. The Outline of Cognitive Philosophy of Language], Irkutsk, OGUP, 2001.

Kubryakova, E., Jazyk $i$ znanie. [Language and Knowledge], Moscow, Jazyki slavjanskoj kultury, 2004.

Lakoff, G., Women, Fire, and Dangerous Things: What Categories Reveal About the Mind, Chicago, University of Chicago Press, 1987.

Lukjanova, N., Ekspressivnaja leksika razgovornogo upotreblenija: Problemy semantiki. [Expressive Conversation Vocabulary: Issues of Semantics], Novosibirsk, Nauka, 1986.

Lyons, J., Introduction to Theoretical Linguistics, Cambridge, Cambridge University Press, 1995.

Ohuy, O., "Linhvistychna teorija znaka v epistemolohichnomu rakursi" [Linguistic Theory of the Sign from the Perspective of Epistemology] in Visnyk Zhytomyrskoho universytetu imeni I. Franka Issue 62, 2012.

Peirce, C., Izbarannye filosofskie proizvedenija. [Selected Works on Philosophy] (N. Golubovich, Transl.), Moscow, Logos, 2000.

Poliuzhyn, M., Funkcionalnyj $i$ kohnityvnyj aspekty anhlijskoho slovotvorennja [Functional and Cognitive Aspects of the English Word-Formation], Uzhhorod, Zakarpattya, 1999.

Poznanski, R. R., "Towards an integrative theory of cognition" in Journal of Integrative Neuroscience 01/02, 2002.

Pryhodko, A., Koncepty $i$ konceptosystemy $v$ cohnityvno-dyskursyvnij paradyhmi linhvistyky [Concepts and Conceptual Systems in the Cognitive-Discoursive Paradigm of Linguistics], Zaporizhzhya, Premier, 2008.

Putiy, O., 'Konceptopole 'antropologicheskoe sostojanie' (na materiale nemeckogo jazyka)" [The Conceptual Field "Anthropological State" A Case Study of German Language], in Nova filolohija Issue 24, 2006.

Schleifer, R., "The semiotics of sensation: A. J. Greimas and the experience of meaning" in Semiotica Issue 214, 2017.

Sechehaye, A., Programma i metody teoretičeskoj lingvistiki: psihologija jazyka [Programme and Methods of Theoretical Linguistics: Psychology of Language] (V.M. Alpatov, Transl.), Moscow, Editorial URSS, 2003.

Selivanova, O., "Classeme" in Suchasna linhvistyka: terminolohichna encyklopedija [Modern Linguistics: Terminological Encyclopaedia], Poltava, Dovkillja-K, 2006. 
Serebrennikov, B. and Elena Kubryakova, eds., Rol chelovecheskogo factora v jazyke: Jazyk I myshlenie. [The Role of Human Factor in Language: Language and Thinking], Moscow, Nauka, 1988.

British National Corpus (BYU-BNC), Corpus.byu.edu. Web. 25 September 2017.

Toporova, V., "Konceptualno-semanticeskij blok kak edinica lingvisticeskogo opisanija" [Conceptual-Semantic Block as a Unit of Linguistic Description] in International Congress on Cognitive Linguistics, Ed. Nikolaj Boldyrev, 2008.

Ufimceva, A., Tipy slovesnyh znakov [Types of Verbal Signs], Moscow, Editorial URSS, 2004.

Volf, E., Funkcionalnaja semantika ocenki [Functional Semantics of Evaluation], 2nd ed., Moscow, 2002.

\section{BIONOTE}

ANNA ZASLONKINA, Ph.D. is a Senior Lecturer in the Department of Communicative Linguistics and Translation at Fedkovych Chernivtsi National University, Ukraine. Her primary area of scholarly research is anthropocentric paradigm centered on the categories of observer and observable, when the human organism is viewed as a holistic basis for construing divergent phenomena of perception. This linguistic principle was reflected in a number of her publications among which "The Conceptual Outline of Perception in Terms of Greimassian Semiotic Theory" in Advanced Education No 8 / 2018 and "Text-Poietic Mechanisms: the Role of Perception, Cognition, and Emotions in Shaping Fictional Reality" in Multidimensional Space of Philological Studies, "Ruta" Publishing House, 2020.

Email: annav.zaslonkina@gmail.com 
